\title{
Perspectives of Heart Vessels and Transplantation in Central Asia
}

To answer the question, why do we need a new medical journal in Central Asia, it is essential to understand that with transition to the new standards of scientific research in majority of Central Asian countries, the crucial need in change of approaches in biomedical publishing corresponding to worldwide standards has emerged. A sharp transition to new standards in science in several countries like Kyrgyzstan, Kazakhstan and Uzbekistan caused situation, when:

1. State policy requirements to scientific research in these countries become equivalent to generally accepted in the world.

2. Development in medicine and medical technologies in these countries made necessary new requirements for academic advancement publications in journals indexed in PUBMED, Scopus, Web of Science and PMC.

3. Modern mentality of researchers demands new platform for expression of thoughts and ideas.

4. Condition of medical periodical journals, published in Central Asian countries do not always conform the contemporary requirements.

5. Availability of research articles published in journals, implementing requirements of international scientific publishing standards in Central Asia is limited.

To solve these problems and promote further development of science and scientific publishing in Central Asia, the group of enthusiasts has established a new multidisciplinary journal Heart Vessels and Transplantation that conforms, all requirements of international worldwide scientific publishing. We are confident that our journal will not be only the basis for publications of research articles but also a platform for science education, and a flagman for all science system in Central Asia.

We would like also to inform our readers that starting 2018 journal will be indexed in 2 more databases.

In this issue, you can find updated editorial board of our journal. On behalf of HVT editors, we welcome new section editor - Pascal Meier, London, UK and Geneva Switzerland; and international editorial board members: Ayan Abdrakhmanov, Astana, Kazakhstan; Kuat Abzaliev, Almaty, Kazakhstan; Usen Baisakov, Bishkek, Kyrgyzstan, Sok-Sithihan Bun, Monaco, Monaco, France; Vierra Illikova, Bratislava, Slovakia; Alexei Kim, Moscow, Russia; Panagiotis Koudounis, Athens, Greece; Lubica Palkovikova-Murinova, Bratislava, Slovakia; Adam Stanczhyk, Warsaw, Poland; Raikhan Tuleyutaeva, Semei, Kazakhstan; Bakyt Tynalieva, Bishkek, Kyrgyzstan; Yersin Zhunussov, Semei, Kazakhstan. We look forward for our collaboration in providing the best practices of unbiased peer-review of manuscripts submitted to our journal.

Taalaibek Kudaiberdiev Deputy Editor, Heart-Vessels and Transplantation Bishkek, Kyrgyzstan 